\title{
Ambulatory photographic screening for diabetic retinopathy in nursing homes
}

S Anderson', DM Broadbent', JYS Swain², JP Vora ${ }^{3}$ and SP Harding

\begin{abstract}
Purpose To evaluate the feasibility and cost of screening for diabetic eye disease in homebound nursing home residents not attending a systematic screening programme. Methods Postal survey identification of residents with diabetes in all nursing homes in Liverpool. An ophthalmologist and nurse performed Bailey-Lovie logmar visual acuity (VA), portable slit-lamp examination, fundus photography, and subjective assessment of ability to cooperate with treatment in a sample of homes. Modified Wisconsin photographic grading was performed. Screen-positive patients were invited to a dedicated assessment clinic. Sight-threatening diabetic eye disease (STED) was defined as any of: moderate preproliferative retinopathy or worse, circinate maculopathy, or exudate within 1 disc diameter of fixation.
\end{abstract}

Results A total of 54 (78\%) nursing homes responded reporting 199/2427 (8.2\%) residents with diabetes. Of these, $64 / 80(80 \%)$ residents in $\mathbf{1 7}$ homes were examined: VA possible in 50 (78\%); slit-lamp examination in $56(88 \%)$; gradable photographs in at least one eye in 34 (53\%); STED in 12 (35\%) patients. In all, $35(70 \%)$ patients had Snellenequivalent VA worse than 6/12 in the better eye, of whom $13(26 \%)$ were worse than $6 / 60$. Of 29 screen positive patients, 12 attended the assessment clinic: one was unable to cooperate outside the home; 11 continue under ophthalmic review, four for previously undetected STED of which one listed for laser photocoagulation. Total cost $£ 16,980$; cost per screen event $£ 60.30$.

Conclusions Systematic eye screening in homebound patients with diabetes detects disease but follow-up and treatment is only feasible in a small proportion and at high cost. Alternative targeted assessment is recommended.
Eye (2003) 17, 711-716. doi:10.1038/

sj.eye. 6700487

Keywords: diabetes mellitus; diabetic retinopathy; screening; aged; homebound persons; cost and cost analysis

\section{Background}

Early treatment for retinopathy is effective in preventing visual loss caused by diabetes, ${ }^{1-3}$ and screening for diabetic eye disease has been shown to be cost-effective. ${ }^{4}$ As a result, a national risk reduction programme based on standardised screening has recently been proposed. ${ }^{5}$ Key issues in such a programme include equity of access and maximised coverage.

Diabetes is common in the elderly with reported prevalence rates of approximately $10 \%,{ }^{6-8}$ and population-based studies have shown increasing prevalence of diabetes with increasing age..$^{7-10}$ This group is more likely to require full time nursing care because of the medical complications of diabetes.

A systematic community-based photographic screening programme for diabetic retinopathy was established in Liverpool in 1991 and has demonstrated good sensitivity and specificity. ${ }^{11,12}$ Patients with diabetes are identified by the general practitioner (GP) and invited to attend for screening at the GP practice. Nursing home residents are included but patients who are judged by carers or professionals as unable to leave the home, for whatever reason, cannot be screened.

In this report, we present the results of a study on the feasibility of screening by a visiting team of health professionals trained in the use of portable equipment in this important group of patients with diabetes. The prevalence of sight-threatening diabetic eye disease (STED)
${ }^{1}$ St Paul's Eye Unit Royal Liverpool University Hospital

Liverpool, UK

${ }^{2}$ Liverpool Diabetes Eye Centre

Royal Liverpool University Hospital

Liverpool, UK

${ }^{3}$ Department of Diabetes and Endocrinology Royal Liverpool University Hospital

Liverpool, UK

Correspondence:

$S$ Anderson

Liverpool Diabetes

Eye Centre

Royal Liverpool University

Hospital

Prescot Street

Liverpool L7 8XP, UK

Tel: + 441517062419

Fax: + 441517062419

E-mail: asarah@

hotmail.com

Received: 28 March 2002 Accepted: 17 December 2002

Proprietary interest: None 
and treatable eye disease was measured and estimates of cost were made.

\section{Methods}

The local nursing home liaison officer surveyed all registered nursing homes for a list of residents with diabetes. Nursing homes reporting more than one resident with diabetes were invited to take part in a pilot ambulatory photographic screening study. The GP responsible for each home, and a relative, where necessary, was contacted for prior approval.

A single ophthalmologist experienced in retinopathy grading (SA), and one of three diabetes support nurses (BM, HH, PD) from the Liverpool Diabetes Eye Centre visited each home. The equipment required was easily carried in a private car.

The mobility of the resident was recorded as walking (with or without aid), wheelchairbound, roombound or bedbound.

Best VA using a Bailey-Lovie logmar chart at $3.8 \mathrm{~m}$ was measured. Pupils were dilated with guttae tropicamide $1 \%$. After a period of at least $20 \mathrm{~min}$, but not more than $1 \mathrm{~h}$, the ophthalmologist performed slit-lamp examination using the 904 Portable Slit Lamp (Clement Clarke). The lens was graded for opacity using the LOCS III system. ${ }^{13}$ Significant cataract was defined as LOCS grade 4 or greater for cortical and nuclear cataract and any degree of posterior subcapsular cataract. Other causes of media opacity or inadequate pupil dilatation were recorded. Six field $30^{\circ}$ fundus photography (disc, macula, and four quadrants) was performed with a hand-held Kowa Genesis fundus camera and recorded on Kodak 200 ASA slide film. A clear image of the disc and macula was regarded as the minimum acceptable if all six could not be tolerated. Ability to achieve satisfactory photography was measured against three criteria: view; cooperation; and physical bar to camera positioning (eg due to posture).

Transparencies were projected onto a standard screen (Slidex, Japan) and graded by two independent observers (SA, DMB). As a result of the practical difficulties of screening a population with physical and mental problems, a specific definition of image quality was developed for this study:

- Grade 1. Good image of disc and macula and adequate image of temporal arcades

- Grade 2. Quality sufficient to determine whether sight-threatening changes present/absent but accurate grading not possible.

- Grade 3. Ungradable.

Modified Wisconsin grading for disease, as previously described, was used throughout (Table 1). ${ }^{11}$ Screen positive was defined as mild preproliferative retinopathy or worse, circinate maculopathy, exudate within 1 disc diameter of fixation, presence of laser scars, or ungradable photographs. STED was defined as any of: moderate preproliferative retinopathy or worse; circinate maculopathy or an exudate within 1 disc diameter of

Table 1 Modified Wisconsin grading system used in the Liverpool Diabetic Eye Screening Service

\begin{tabular}{|c|c|}
\hline Grading & Definition \\
\hline \multicolumn{2}{|c|}{ (A) Retinopathy } \\
\hline 10 & No retinopathy \\
\hline 20 & Haemorrhages or microaneurysms $<$ ETDRS ${ }^{14}$ standard photograph $2 \mathrm{~A}$ \\
\hline 30 & Haemorrhages or microaneurysms $\geq$ ETDRS standard photograph $2 \mathrm{~A}$, and/or one to six cotton wool spots \\
\hline 40 & $\begin{array}{l}\geq 6 \text { cotton wool spots, and/or venous changes in one quadrant, and/or intraretinal microvascular anomaly } \\
<\text { ETDRS standard photograph } 8 \mathrm{~A}\end{array}$ \\
\hline 60 & Proliferative retinopathy and/or panretinal photocoagulation and/or fibrovascular proliferation \\
\hline 70 & High-risk characteristics ${ }^{15}$ \\
\hline 71 & Traction retinal detachment and/or no fundal view because of vitreous blood \\
\hline 90 & Ungradable \\
\hline \multicolumn{2}{|c|}{ (B) Maculopathy } \\
\hline 1 & $<50 \%$ certainty of presence of exudate \\
\hline 2 & Exudate $>1$ disc diameter from fixation \\
\hline 3 & Ring of exudates within macula, $\geq 1$ disc area in size, but not within 1 disc diameter of fixation \\
\hline 4 & Exudates within 1 disc diameter of fixation, and/or presence of focal or grid photocoagulation scars \\
\hline 8 & Exudates because of other disease, for example, vein occlusion, CNVM \\
\hline 90 & Ungradable \\
\hline
\end{tabular}

Sight-threatening changes in bold. 
fixation. Subjective assessment of ability to cooperate with hospital follow-up and laser photocoagulation was also made.

Screen-positive patients not currently under the care of an ophthalmologist were invited for slit-lamp biomicroscopy in a dedicated assessment clinic staffed by three ophthalmologists specialising in medical retina (SA, DMB, SPH). Subjects who were unable to cooperate with fundus photography were not invited to this clinic, as they would not be able to cooperate with further examination or treatment. For patients already under an ophthalmologist the casesheet was checked for current status.

\section{Results}

A total of $54 / 74(73 \%)$ registered nursing homes located within the boundaries of Liverpool Health Authority replied to the nursing home liaison officer, and reported 199 diabetic residents from a total potential population of 2427 (based on maximum number of beds available in all homes surveyed), giving a point prevalence rate for diabetes of $8.2 \%$.

A total of 80 residents with diabetes in 17 nursing homes were identified for the pilot study. Screening commenced 4 months after and was completed 8 months after the original survey was initiated. In all, 64/80 (80\%) residents were seen on the appointed screening days: $8 / 80(10 \%)$ had died, 3/80 (3.8\%) were hospital inpatients, and $5 / 80(6.3 \%)$ did not wish to participate. The average age of those screened was 80 years (range 51-97); male to female ratio was 1: 1.46. A total of 21 (33\%) were classified as walking, $38(59 \%)$ wheelchairbound; one roombound because of agoraphobia, and four $(6 \%)$ bedbound.

Details on diabetes management were available on the day of examination for $59(92 \%)$ residents: diet alone 17 (27\%); oral hypoglycaemics 24 (38\%), insulin 16 (25\%). Two residents said they had been told they were 'no longer diabetic', one of whom had formerly been on insulin treatment.

Vision was recordable in $50(78 \%)$ residents and portable slit-lamp examination was possible in $56(88 \%)$ residents (112 eyes). VA was not recordable in six subjects with dysphasia but all were successfully examined with the slit lamp. Vision was recorded as worse than +0.3 log units $(6 / 12$ Snellen equivalent) in the better eye in $35 / 50(70 \%)$ and worse than $+1.0(6 / 60)$ in $13 / 50(26 \%)$ residents. Three of the residents with registrable vision were already on the blind register. Causes of reduced vision are shown in Table 2.

Photographs were unobtainable in 17 patients: nine could not cooperate with any part of the examination, four could not be photographed because of posture, two
Table 2 Causes of reduced visual acuity detected at first examination in 64 nursing home residents examined for sight threatening eye disease in Liverpool

\begin{tabular}{lrc}
\hline & $\begin{array}{r}V A>+0.3^{\mathrm{a}} \\
(<6 / 12)\end{array}$ & $\begin{array}{l}V A>+1.0^{\mathrm{a}} \\
(<6 / 60)\end{array}$ \\
\hline Cataract & $10(29 \%)$ & $2(15 \%)$ \\
Diabetic eye disease & $5(14 \%)$ & $3(23 \%)$ \\
Macular degeneration & $4(11 \%)$ & $3(23 \%)$ \\
Other & $4(11 \%)$ & $3(23 \%)$ \\
Unknown & $12(34 \%)$ & $2(15 \%)$ \\
\hline
\end{tabular}

${ }^{a}$ Visual acuity measured in log units using Bailey-Lovie Chart, with Snellen equivalent in brackets.

had dense cataracts with no red reflex, and two refused to take part on that day.

At least one photograph was taken in 47 residents $(73 \%)$. Photographs were gradable in at least one eye in $34 / 64$ (53\%) residents; however, photographs were gradable in both eyes in only 20/64 (31\%) residents. A total of 40 eyes photographed were ungradable. The cause for ungradable photographs was often multifactorial. An attempt was made to identify the main reason for photographic failure: cataract in 16 eyes, posterior capsule thickening in six eyes, patient posture in four eyes, inability to tolerate camera flash in six eyes, small pupil in one eye, vitreous haemorrhage in one eye, and no identifiable cause on slit-lamp examination in six eyes. A total of 10/64 (16\%) patients are under current ophthalmic care.

The results of grading for retinopathy and maculopathy by worse eye are shown in Table 3. STED was found in 12/34 (35\%) residents. Of twelve patients, four with STED are under current care. Of the six patients with sight-threatening retinopathy, five had evidence of proliferative retinopathy (PDR) and this had been treated in four cases. One patient had moderate preproliferative retinopathy and a further four patients had mild preproliferative retinopathy (PPF). One of the patients with treated retinopathy and under ophthalmic care had obvious active disease with vitreous haemorrhage. The patient with untreated PDR had a single focus of new vessels elsewhere.

Action taken following photographic grading is summarised in Table 4. Where untreatable disease was detected that would allow blind registration the GP was informed. The GP was also informed if the resident was found to have no significant diabetic eye disease or refused to be screened. A total of 29 patients were screen positive by our definition. Of these, one stated at the screening visit that she would refuse any further followup, one was felt to be medically unfit to leave the nursing home, and two were found to have end-stage disease that could not be treated. Three patients, that would not be 
Table 3 Level of retinopathy/maculopathy in 64 nursing home residents screened for sight-threatening diabetic eye disease in Liverpool

\begin{tabular}{lr}
\hline Level & Number \\
\hline (A) Retinopathy & \\
10 & 15 \\
20 & 7 \\
30 & 4 \\
40 & 1 \\
50 & 0 \\
60 & 2 \\
70 & 0 \\
71 & 2 \\
90 & 30
\end{tabular}

(B) Maculopathy

0

1

2

3

4

8

Grading of the worse eye is recorded where both were gradable, or the gradable eye where only one could be graded.

Table 4 Outcome of photographic screening in 64 nursing home residents in Liverpool

\begin{tabular}{lcr}
\hline Outcome & Number & $(\%)$ \\
\hline Refusing screening & 2 & $(3)$ \\
Medically unfit for screening & 4 & $(6)$ \\
Poor cooperation & 13 & $(20)$ \\
No significant disease found & 7 & $(11)$ \\
Refusing further treatment & 1 & $(2)$ \\
Under current care & 10 & $(16)$ \\
Untreatable disease seen & 8 & $(13)$ \\
Appointment made for assessment clinic & 19 & $(30)$ \\
\hline
\end{tabular}

defined as screen positive by our criteria, were also invited to attend the assessment clinic as they had poor VA that could not be explained by media opacity or communication problems.

The outcome from the assessment clinic is summarised in Table 5. One patient with circinate maculopathy was listed for laser treatment.

The estimated revenue cost for the clinical sessions used in the study (staff plus consumables) was $£ 3228$. Capital costs are detailed in Table 6 and totalled $£ 13752$. Assuming a 7-year capital

depreciation, the direct costs per screen event are $£ 60.30$. Among patients able to comply with hospital, care screening detected one case requiring treatment and three cases with STED requiring follow-up. This gives a cost of $£ 965$ per 'true positive' and $£ 3859$ per treatable case detected.
Table 5 Outcome of assessment clinic in 19 nursing home residents who were screen positive after photographic screening in nursing homes in Liverpool

\begin{tabular}{lc}
\hline Outcome & Number \\
\hline Patient died before appointment & 3 \\
Refused to attend & 2 \\
Unsuitable for follow-up (carer decision) & 2 \\
Unable to cooperate outside nursing home & 1 \\
Follow-up of diabetic disease in clinic & 3 \\
Follow-up of other disease in clinic & 3 \\
Follow-up in general clinic - unsuitable for & 3 \\
photographic screening & \\
Listed for laser treatment & 1 \\
Listed for cataract surgery & 1 \\
\hline
\end{tabular}

Table 6 Table of costs incurred during screening 64 residents of nursing homes in Liverpool for sight-threatening diabetic eye disease using portable examination equipment

\begin{tabular}{|c|c|c|c|}
\hline Expense & Units & $\begin{array}{l}\text { Unit cost } \quad \mathrm{T} \\
\text { (£) }\end{array}$ & $\begin{array}{l}\text { Total cost } \\
\text { (£) }\end{array}$ \\
\hline \multicolumn{4}{|l|}{ (A) Revenue cost } \\
\hline Total SPR time (h) & 72 & 19 & 1371 \\
\hline Total HCA time (h) & 51 & 7 & 362 \\
\hline Total secretarial time $(\mathrm{h})$ & 10 & 9 & 89 \\
\hline $\begin{array}{l}\text { Clinic numbers } \\
\text { (patients seen) }\end{array}$ & 12 & 87 & 1044 \\
\hline $\begin{array}{l}\text { Total travelling } \\
\text { distance (miles) }\end{array}$ & 98 & 1 & 49 \\
\hline Films developed & 25 & 10 & 248 \\
\hline \multirow[t]{3}{*}{ Stationary drops, etc } & & & 65 \\
\hline & & $\begin{array}{l}\text { Total revenue } \\
\text { cost }\end{array}$ & 3228 \\
\hline & & $\begin{array}{l}\text { revenue } \\
\text { cost per } \\
\text { screen }\end{array}$ & 50.43 \\
\hline \multicolumn{4}{|l|}{ (B) Capital (inclusive of VAT) } \\
\hline \multicolumn{3}{|c|}{ Kowa Genesis hand-held fundus camera } & 9394 \\
\hline \multicolumn{3}{|c|}{904 Clement Clarke Portable Slit Lamp } & 4229 \\
\hline \multirow{3}{*}{\multicolumn{2}{|c|}{ Bailey-Lovie vision chart }} & & 129 \\
\hline & & Capital cost & 13752 \\
\hline & & $\begin{array}{l}\text { Capital cost } \\
\text { per screen }{ }^{\mathrm{a}}\end{array}$ & 9.87 \\
\hline Total cost per screen & & & 60.30 \\
\hline
\end{tabular}

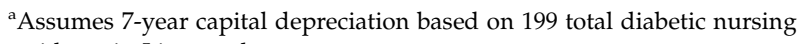
residents in Liverpool.

\section{Discussion}

In this study, we found a prevalence of diabetes in the nursing home population of $8.2 \%$, comparable to the 9.9\% found in a study from an adjacent health authority in $1997 .{ }^{6}$ A survey of nursing homes in the United States the same year reported a lower prevalence at $4.6 \% .^{16}$ There were nearly $50 \%$ more women than men reflecting the greater longevity of the female population. 
The screening method employed in this study required an experienced ophthalmologist or nurse practitioner to perform examinations and to assess the resident's ability to cooperate with further investigation and treatment. As expected, most residents (59\%) required a wheelchair for mobility in the nursing home. Residents with severe mobility problems had difficulty attending a venue outside their normal living arrangements for screening. A fixed fundus camera was difficult to use with the resident seated in a wheelchair and often required the subject to be transferred to a suitable seat. The hand-held camera avoided most of these problems. A further $8 \%$ of residents were room or bedbound. Slit-lamp biomicroscopy was considered necessary, as there was a high probability of ungradable photographs because of media opacity. Photography remained the most difficult part of the examination for most residents, as many were unable to tolerate the strong light source or closeness of the camera. In all, 11 residents could not tolerate photography in either eye and a further three were unable to co-operate with photography in one eye. Photographs were completely unobtainable because of physical disability in only five residents. It was felt that if unable to cooperate with photography, they would also have difficulty with biomicroscopy and certainly laser treatment.

There was a high mortality rate for our subjects with eight dying in the 4-8 month period between identification and screening and a further three dying before assessment could be arranged, 11 (14\%) overall. Other studies have found a mortality rate of $25-33 \%$ in people with diabetes over 60-65 years not resident in nursing homes over a 5-6 year period. ${ }^{9,8}$

In our study, the VA was below 6/12 in the majority of subjects $(70 \%)$ and was a very poor indicator of diabetic eye disease requiring treatment. Not surprisingly, cataract was the most common reason for reduced vision (46\% of eyes), consistent with other studies. ${ }^{17,18}$

(A further $36 \%$ of residents were pseudophakic in one or both eyes.) No clear cause was found for reduced vision in $33 \%$ of our subjects; however, it was not felt to be appropriate to refer them for further investigation in view of their other physical/mental problems. A significant proportion, 13 (26\%), of residents had vision reduced sufficiently to be eligible for partial or blind registration, but this had only been completed in three. Besides providing daily living aid, registration might highlight the awareness of the individual's visual problems to nursing home staff. It is likely that nondiabetic nursing home residents suffer with similar visual impairment, as diabetic eye disease was not the most common cause of reduced VA.

Media opacity was the most common cause for failure to obtain adequate photographs, followed by poor patient cooperation. In 16 eyes, good dilatation was not achieved. Tropicamide alone was used to dilate the pupils. It is possible that with the addition of phenylephrine the view may have been clearer in a few residents, but it is equally likely that these residents had an autonomic neuropathy preventing adequate dilatation.

In the 34 residents with adequate photography, six (18\%) had sight-threatening retinopathy, 7/34 (21\%) had sight-threatening maculopathy, and over a third, (35\%) had STED. This is likely to underestimate the true prevalence of disease, as satisfactory photography was only possible in both eyes in $31 \%$ residents. Of the six patients with sight-threatening retinopathy, five had evidence of PDR, which had been treated in four cases. Four patients had mild PPF, which in Liverpool requires 6 monthly rescreening. The patient with untreated PDR was nonverbal and incapacitated by stroke and laser photocoagulation for this subject was deemed unfeasible.

A total of 29 patients had screen-positive disease. Seven were already under continuing ophthalmic care, two had end-stage disease, one was thought to be medically unfit, by the screening team, to attend clinic, and one refused further treatment at the screening visit. In total, 19 were considered by the screening team to be capable of assessment. However, two were deemed unfit by the nursing home, two refused to attend, and three had died before the appointment date. Of the 12 who attended the hospital assessment clinic, one patient was unable to cooperate outside the nursing home environment, three patients required follow-up for diabetic eye disease, one was listed for cataract extraction, and one patient was listed for laser treatment. After laser and refraction, this patient's VA improved from 5/60 to 6/9 in the affected eye. Unfortunately, the patient died within a year of treatment.

In $71 \%$ of our subjects, no formal arrangements had been made prior to this study for annual eye examinations. It is possible that many of the residents had undergone opportunistic screening by their optician, as was found by Benbow et $a l^{6}$ in a similar population. However, it is well recognised that screening by direct ophthalmoscopy lacks sensitivity ${ }^{11}$ and serious error rates of $30-74^{13} 26^{19}$ and $49 \%{ }^{20}$ have been reported. This is even more likely to be the case in a population with a high rate of sight-reducing cataract.

The cost of running this screening service was $£ 60.30$ per screen event. As a result of the low number of patients that could cooperate with follow-up or treatment, costs per true positive at $£ 965$ and per treatable case at $£ 3859$ were high. These figures compare poorly with the published cost per true positive at $£ 209$ in the Liverpool Diabetic Eye Study, ${ }^{4}$ and the cost per laser-treated patient at $£ 1000$ reported in Dundee. ${ }^{21}$ 
We believe that these costs do not adequately justify the introduction of systematic screening of all residents with diabetes in nursing homes. However, this population should not be ignored. We believe that the provision of diabetes care should include the requirement of a health professional, with regular access, to assess and record annually whether each resident with diabetes would be likely to cooperate with ocular examination and subsequent treatment. Mobile patients should be added to existing screening programmes, while immobile patients or those with media opacity are probably best assessed using slit-lamp biomicroscopy in the hospital setting. There appears to be no effective way of screening and treating those too confused or immobile to cooperate.

In conclusion, although there is a high rate of significant eye disease among the population with diabetes in nursing homes, we have not been able to justify systematic photographic screening due mainly to poor cooperation from confused patients and a high rate of media opacity producing a prohibitively high cost. Population screening should not be performed where individuals cannot be treated or for whom treatment will not increase their chances of improving or maintaining quality of life.

\section{Acknowledgements}

We acknowledge the help Brian, Helen, and Pauline for their nursing assistance on visits. We also thank the ophthalmic photographic staff for their help with processing of film.

\section{References}

1 Diabetic Retinopathy Study Research Group. DRS Group \#8. Photocoagulation treatment of proliferative diabetic retinopathy. Ophthalmology 1981; 88: 583-600.

2 Lee CM, Olk RJ. Modified grid laser photocoagulation for diffuse diabetic macular edema. Long-term results. Ophthalmology 1991; 98: 1594-1602.

3 Early Treatment Diabetic Retinopathy Study Research Group. Photocoagulation for diabetic macular oedema. Int Ophthalmol Clin 1987; 27: 265-272.

4 James M, Turner DA, Broadbent DM, Vora J, Harding S. Cost effectiveness analysis of screening for sight threatening diabetic eye disease. BMJ 2000; 320: 1627-1631.

5 Garvican L, Clowes J, Gillow T. Preservation of sight in diabetes: developing a national risk reduction programme. Diabetic Med 2000; 17: 627-634.
6 Benbow S J, Walsh A, Gill G V. Diabetes in institutionalised elderly people: a forgotten population? BMJ 1997; 314: 1868.

7 Stolk RP, Vingerling JR, de Jong PTVM, Dielemans I, Hofman A, Lamberts SWJ et al. Retinopathy, glucose, and insulin in an elderly population: the Rotterdam study. Diabetes 1995; 44: 11-15.

8 Rockwood K, Awalt E, MacKnight C, McDowell I. Incidence and outcomes of diabetes mellitus in elderly people: report from the Canadian study of health and aging. Can Med Assoc J 2000; 162: 769-772.

9 Conen DL, Neil HAW, Thorogood M, Mann JI. A population-based study of the incidence of complications associated with type 2 diabetes in the elderly. Diabetic Med 1991; 8: 928-933.

10 Hirvelä A, Laatikainen L, Diabetic retinopathy in people aged 70 years or older. The Oulu eye study. Br J Ophthalmol 1997; 81: 214-217.

11 Harding SP, Broadbent DM, Neoh C, White MC, Vora J. Sensitivity and specificity of photography and direct ophthalmoloscopy in screening for sight threatening eye disease: the Liverpool diabetic eye study. BMJ 1995; 311: 1131-1135.

12 Broadbent DM, Harding SP, James M, Vora JP. Does stereoscopic macular photography improve the detection of macular oedema: a further sensitivity and specificity analysis. Diabetic Med 2000; 17 (Suppl 1): P56.

13 Chylack LT, Wolfe JK, Singer DM, Leske C, Bullimore MA, Bailey IL et al. The lens opacities grading system III. Arch Ophthalmol 1993; 111: 831-836.

14 Early Treatment Diabetic Retinopathy Study Research Group. Grading diabetic retinopathy from stereoscopic color fundus photographs - an extension of the Modified Airlie House Classification. ETDRS Report \#10. Ophthalmology 1991; 98: 786-806.

15 Early Treatment Diabetic Retinopathy Study Research Group. Fundus photographic risk factors for progression of diabetic retinopathy. ETDRS report \#12. Ophthalmology 1991; 98: 823-833.

16 Gabrel C, Jones A. The national nursing home survey: 1997 summary. National Center for Health Statistics. Vital Health Stat 2000; 13(147): 1-121.

17 Tielsch HM, Javitt JC, Coleman A, Katz J, Sommer A. The prevalence of blindness and visual impairment among nursing home residents in Baltimore. N Eng J Med 1995; 332: 1205-1209.

18 Wormald RP, Wright LA, Courtney P, Beaumont B, Haines AP. Visual problems in the elderly population and implications for services. BMJ 1992; 304: 1226-1229.

19 Sussman EJ, Tsuarias WG, Sarper KA. Diagnosis of diabetic eye disease. JAMA 1982; 247: 3231-3234.

20 Moss SE, Klein R, Kessler SD, Richie KA. Comparison between ophthalmoscopy and fundus photography in determining severity of diabetic retinopathy. Ophthamology 1985; 92: 62-67.

21 Leese GP, Ahmed S, Newton RW, Jung RT, Ellingford A, Baines $\mathrm{P}$ et al. Use of mobile screening unit for diabetic retinopathy in rural and urban areas. BMJ 1993; 306: 187-189. 